\title{
Synthesis of Magnesium Silicate Hydrate as an Adsorbent for Different Dyes
}

\author{
PASINEE PANITH ${ }^{1}$, WORAWAT WATTANATHANA ${ }^{1}$, WANCHAI DEELOED ${ }^{2}$, RATTHAPIT \\ WUTTISARN ${ }^{1}$, SUTTIPONG WANNAPAIBOON ${ }^{3}$, YURANAN HANLUMYUANG ${ }^{1}$, \\ NOLLAPAN NOOTSUWAN ${ }^{1}$, CHATCHAI VERANITISAGUL ${ }^{4}$ and APIRAT LAOBUTHEE ${ }^{1 *}$
}

\author{
'Department of Materials Engineering, Faculty of Engineering, Kasetsart University, Ladyao, \\ Chatuchak, Bangkok 10900, Thailand. \\ ${ }^{2}$ Department of Chemistry, Faculty of Science, Kasetsart University, Ladyao, Chatuchak, \\ Bangkok 10900, Thailand. \\ ${ }^{3}$ Synchrotron Light Research Institute, 111 University Avenue, Suranaree, Muang, \\ Nakhon Ratchasima 30000, Thailand. \\ ${ }^{4}$ Department of Materials and Metallurgical Engineering, Faculty of Engineering, \\ Rajamangala University of Technology Thanyaburi, Pathumthani 12110, Thailand. \\ *Corresponding author E-mail: fengapl@ku.ac.th \\ http://dx.doi.org/10.13005/ojc/350422
}

(Received: July 02, 2019; Accepted: August 01, 2019)

\begin{abstract}
Magnesium silicate hydrate was synthesized for using as an adsorbent for different commercial organic dyes. X-ray diffraction (XRD) confirmed the crystalline phase of magnesium silicate hydrate. Some characteristic absorption bands of the magnesium silicate hydrate structure were observed in the Fourier transform infrared spectroscopy (FTIR) spectrum which supported the result identified from XRD data. Analysis of surface area and porosity by surface area analyzer showed that the synthesized magnesium silicate had high surface area of $634.63 \mathrm{~m}^{2} / \mathrm{g}$ and also showed the average BJH pore size of $3.72 \mathrm{~nm}$. Insight into the sorption isotherm curve, the hysteresis characteristic was clearly observed suggesting a presence of mesopores within the obtained material. Dye adsorption study revealed that the synthesized adsorbent had the strongest affinity to the cationic dye (methylene blue) on account of the negative charge on the surface of the adsorbent. Hence, the adsorption of methylene blue was reached the equilibrium at the fastest time. In all, the results showed a possibility to apply this prepared magnesium silicate materials as a selective adsorbent for cationic dyes.
\end{abstract}

Keywords: Magnesium silicate, Hydrothermal synthesis, Adsorbent, Dyes.

\section{INTRODUCTION}

Dyes are usually applied to materials to provide desired colors. They are widely employed in different industries e.g., pharmaceutical, food, cosmetics, plastics, photographic, paper industries, among others ${ }^{1}$. Dyes can be adhered to a variety of surfaces ascribed to the formation of covalent

This is an Open Access article licensed under a Creative Commons license: Attribution 4.0 International (CC- BY). Published by Oriental Scientific Publishing Company @ 2018

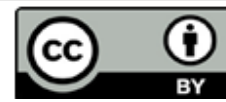


bonds, coordination complexes with certain metal ions, or even via physical adsorption like Van der Waals $(\mathrm{VdW})$ attractions ${ }^{2}$. There are many types of dyes which can be categorized by their applications and/or different chemical structures. The key feature within organic dyes attributed to their intense colors is the group of atoms called chromophores. These chromophore centers consist of diverse functional groups, such as azo $(-\mathrm{N}=\mathrm{N}-)$, anthraquinone, methine (-CH-), nitro (-NO $\left.\mathrm{NO}_{2}\right)$, carbonyl (-CO-), and others. In addition, there are electrons withdrawing or donating substituents so-called auxochromes, which generate and/or intensify the color of the chromophores. Among those, amine, carboxyl, sulfonate, and hydroxyl groups are the most common-used functional groups ${ }^{3}$.

It is known that many thousand dyes and pigments are widely used in industry, and hence several tons of synthetic dyes are annually produced worldwide ${ }^{4}$. In addition, the heightened demand for textile products increases the demand of synthetic dyes production. The immensive proportional use of synthetic dyes and inefficient dyeing process contribute to the dye wastewater, which nowadays becomes one of the crucial sources of severe pollutions ${ }^{5}$. At the end of dyeing cycles, used dye substances are typically led to be passed through a wastewater treatment and later be released to the natural environments, i.e. commonly into canals and rivers. Due to their chemical inertness in the ambient condition as well as their high stability to light, the used dyes vastly remain as chemical pollutants within the eco-systems ${ }^{6}$. For instance, in case of the "Reactive Blue 19" dye, it requires about 46 years to let half of the amounts to be biodegraded via hydrolysis at $\mathrm{pH}$ 7 and $25^{\circ} \mathrm{C}^{7}$. Based on this circumstance, most of dyes and pigments are strategically designed to be resistant for biodegradation in order to extend their utilization-lifetime in products. Hence, investigation of effective methods to remove dye residues in nature is of concern.

Recently, the conventional methods of dye removal from contaminated water involve several processes, such as flocculation ${ }^{8}$, ozonation ${ }^{9}$, membrane filtration ${ }^{10}$ and photocatalytic and biological degradation ${ }^{11}$. Among these treatments, adsorption process is considered as one of the most efficient routes owing to its relatively low-cost, simple deployment, and short operation period ${ }^{12-14}$. In details, the dye adsorption can be broken down into several steps; (i) the dye molecules first encounter the boundary layer between the adsorbent and the adsorbate; (ii) then they diffuse from the boundary film onto adsorbent surface; (iii) finally they diffuse into the porous structure of the adsorbent. Certain adsorbing materials have been investigated to remove synthetic dyes from the wastewater such as activated carbon ${ }^{15-16}$, hydroxides ${ }^{17-20}$, inorganic clays ${ }^{21-23}$, among others. Because of its non-toxicity, low cost, superior adsorption capacity, fast adsorption rate and high availability, magnesium silicate had become one of the most interesting adsorbent materials ${ }^{24}$. In this paper, we examined the affinity of the synthesized magnesium silicate towards the adsorption characteristics of some cationic and anionic dyes. The detailed characterizations are thoroughly explained hereafter and indicate herein the potential use of magnesium silicate for dye removal.

\section{EXPERIMENTAL}

\section{Materials preparation}

The starting materials, magnesium nitrate hexahydrate $\left(\mathrm{Mg}\left(\mathrm{NO}_{3}\right)_{2} \cdot 6 \mathrm{H}_{2} \mathrm{O}\right)$ was received from Merck \& Co. while sodium silicate $\left(\mathrm{Na}_{2} \mathrm{SiO}_{3}\right)$ was supplied from TIAN-NAM Chemical Industrial Trade. Propylene glycol-400 was a commercialgrade product proving by Suksapanpanit, Thailand. Magnesium silicate powders were prepared by a hydrothermal method. $\mathrm{Na}_{2} \mathrm{SiO}_{3}$, with the volume of $0.9 \mathrm{~mL}$ was dissolved in water, while $1.48 \mathrm{~g}$ of $\mathrm{Mg}\left(\mathrm{NO}_{3}\right)_{2} \cdot 6 \mathrm{H}_{2} \mathrm{O}$ was dissolved in the mixture of propylene glycol-400 and ethanol with the volume ratio of 3 to 1. After the two solutions were mixed, a white precipitate was formed. The $\mathrm{pH}$ of this step was kept at the value of 10 . The obtained mixture was transferred into an autoclave and treated at $150^{\circ} \mathrm{C}$ for 24 hours. The hydrothermally treated products were further filtered and washed with distilled water several times until the $\mathrm{pH}$ of the washing solution was at 7 . The obtained product was then dried at $80^{\circ} \mathrm{C}$ overnight prior to material characterizations and adsorption study.

\section{Materials Characterization}

Powder X-ray diffraction (XRD) was performed at ambient temperature at Beamline1.1W (Multiple X-ray Techniques) at Synchrotron Light Research Institute, Thailand using the 
monochromatic synchrotron X-ray radiation of the energy $8046 \mathrm{eV}$ (wavelength of $1.5409 \AA$, equally to $\mathrm{Cu} \mathrm{K} \alpha$ radiation). The powder sample was packed in Kapton capillary with a diameter of $0.5 \mathrm{~mm}$ and aligned using goniometer head. It should be noted that the capillary was constantly rotated during the powder XRD measurement. The diffraction pattern was recorded by a strip detector (Mythen6K 450, Dectris $\AA$ ) in the $2 \theta$ range of $10-90^{\circ}$. Fourier transform infrared spectrophotometer (Bruker Alpha) was used to reveal chemical functional groups in the prepared magnesium silicate powder before the dye adsorption process. The sample was thoroughly grounded with $\mathrm{KBr}$ and uniaxially pressed into a pellet and then used for the measurement in transmission mode. All peaks in the range $4000-400 \mathrm{~cm}^{-1}$ were recorded with a spectral resolution of $2 \mathrm{~cm}^{-1}$. The morphology study was done under a scanning electron microscope (SEM, FEI Quanta 450). The sample was preliminarily sputter-coated with gold to avoid charging problem. Nitrogen adsorption-desorption measurements were carried out using a Micromeritics 3Flex surface area and porosity analyzer. The samples were degassed at $200^{\circ} \mathrm{C}$ for $24 \mathrm{~h}$ prior to the nitrogen gas adsorption measurement. The specific surface area (SBET) of the prepared powder was calculated in accordance with the BET (Brunauer-Emmett-Teller) principle referring to the nitrogen adsorption isotherm at $77 \mathrm{~K}$. Moreover, full adsorption and desorption isotherms were also recorded.

\section{Dye adsorption study}

The weight of the prepared magnesium adsorbent was $0.1 \mathrm{~g}$ for all experiments. The dyes used in this work were methylene blue (MB), reactive blue 19 (RB19), and methyl orange (MO). MB is a cationic dye while RB19 and MO are anionic dyes ${ }^{25}$. The concentrations of MB, RB19 and MO used in the whole experiments were fixed at $50 \mathrm{ppm}$. The adsorbent was added to the $20 \mathrm{~cm}^{3}$ of solutions of each dye, and then the mixtures were shaken for 6 hours. Samplings of the reaction mixture were regularly uptaken out every $60 \mathrm{~min}$ in order to measure their absorbance at $\lambda_{\max }$ by using an ultraviolet-visible spectrometer (Shimadzu PhamaSpec 1700 model). The sampling solutions were centrifugated prior to the UV-Vis absorption study.

The quantity adsorbed was calculated by the following equation:

$\mathrm{q}_{\mathrm{e}}=\left[\left(\mathrm{C}_{0}-\mathrm{C}_{\mathrm{f}}\right) \mathrm{V}\right] / 1000 \mathrm{~W}$,
Where $\mathrm{q}_{\mathrm{e}}$ is the amount of dye adsorbed by the adsorbent in $\mathrm{mg} \mathrm{g}^{-1} . \mathrm{C}_{0}$ and $\mathrm{C}_{\mathrm{f}}$ are initial and final concentration in $\mathrm{mg} \mathrm{dm}^{-3}$ in the solution, $\mathrm{V}$ and $W$ represent the volume of solution $\left(\mathrm{dm}^{-3}\right)$ and weight of the adsorbent (g), respectively. The effect of $\mathrm{pH}$ on the MB adsorption was also examined by adjusting the $\mathrm{pH}$ of the solutions to $5,6,7,8$ and 9 using 1 $\mathrm{M} \mathrm{HCl}$ hydrochloric acid or $1 \mathrm{M}$ sodium hydroxide. Moreover, the adsorption characteristic was studied with a variety of the adsorbent contents, namely 0.01 g, $0.05 \mathrm{~g}$ and $0.10 \mathrm{~g}$. However, the concentration of the MB dye was used $100 \mathrm{ppm}$ instead of 50 ppm in these studies to emphasize the effects of $\mathrm{pH}$ and the adsorbent contents on MB adsorption characteristics.

\section{RESULTS AND DISCUSSION}

\section{Material Characterization}

The diffraction pattern of the solid magnesium silicate prepared from hydrothermal method is shown in (Fig. $1 \mathrm{~A})$. It was observed that the diffraction peaks were corresponding to the crystalline phase of magnesium silicate hydrate $\left(2 \mathrm{MgO}_{3} 3 \mathrm{SiO}_{2} \cdot 2 \mathrm{H}_{2} \mathrm{O}\right)$ rather than those of non-hydrated $\mathrm{MgSiO}_{3}$ phase. Although the degree of crystallinity of the hydrated product is relatively low (mainly due to the lack of the final calcination step), this result indicated the successful synthesis of magnesium silicate hydrate. A key imperative to having the hydrated form is to avoid the agglomeration of particles, which could later lead to a poor performance for dye adsorption. Fourier transform infrared (FTIR) spectrum of the obtained magnesium silicate hydrate is displayed in (Fig. 1 B). The broad peak around $3450 \mathrm{~cm}^{-1}$ was attributed to the $\mathrm{O}-\mathrm{H}$ stretching vibration ${ }^{26-27}$ of the moisture adsorbed on the surface of the magnesium silicate hydrate and/or the water of crystallization in the crystal structure of magnesium silicate hydrate. There is an absorption around 1640 $\mathrm{cm}^{-1}$ corresponding to $\mathrm{O}-\mathrm{H}$ bending vibration and confirming the presence of $\mathrm{O}-\mathrm{H}$ stretching peak as discussed previously ${ }^{28-29}$. Characteristic peak of magnesium silicate structure (Si-O-Si symmetrical stretching vibration) was found at $1016 \mathrm{~cm}^{-1}{ }^{30}$. Moreover, the bands at 662 and $462 \mathrm{~cm}^{-1}$ were arisen from $\mathrm{Si}-\mathrm{O}$ bending and $\mathrm{Mg}-\mathrm{O}$ vibration, respectively ${ }^{30}$. The scanning electron microscopic (SEM) image of the prepared magnesium silicate hydrate is illustrated in (Fig. 1 C). Evidently, it was observed that the microstructure of the prepared magnesium silicate was plate-like particles due 
to the preferred spatial growth of the magnesium silicate hydrate particles during the hydrothermal crystallization. The size distribution of magnesium silicate hydrate sheet is depicted in (Fig. 1 D). The mean thickness was found to be $42 \pm 9 \mathrm{~nm}$. Full nitrogen adsorption isotherms of the sample are shown in (Fig. 2 A) while BJH pore size distribution from

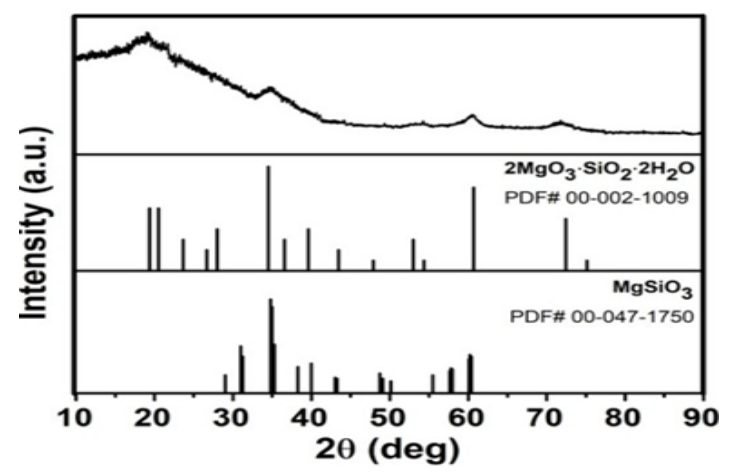

(A)

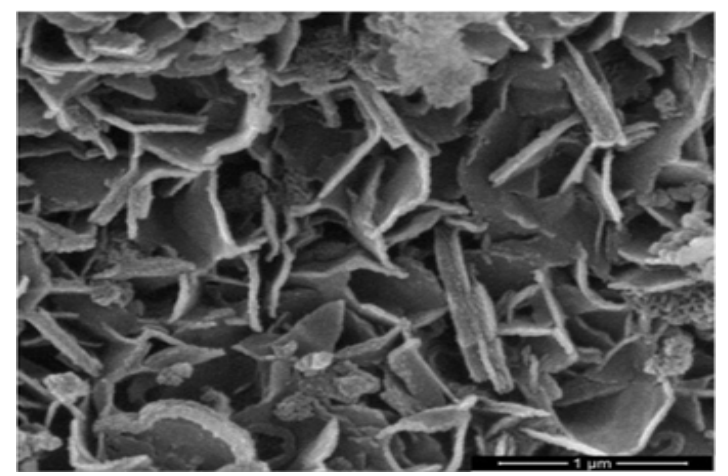

(C) desorption isotherm is portrayed in (Fig. 2 B). The isotherms suggested a mesoporous characteristic as the hysteresis loop was clearly observed due to the different pathways of $\mathrm{N}_{2}$ adsorption and desorption after the monolayer adsorption. In addition, the mesopores were presented within the material with an average size of $3.7 \mathrm{~nm}$ according to the $\mathrm{BJH}$ analysis.

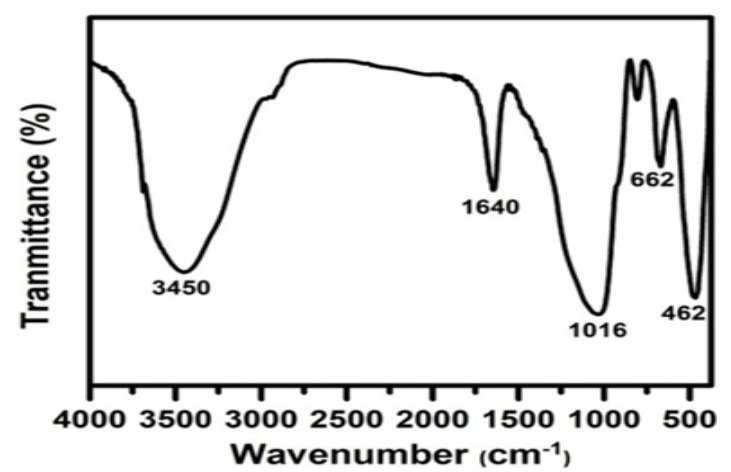

(B)

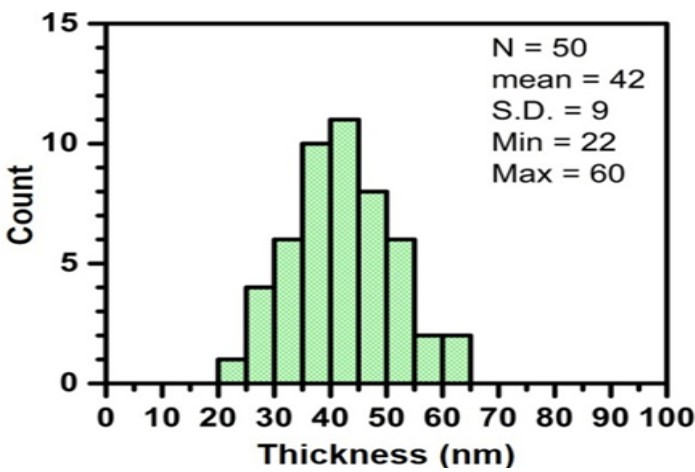

(D)

Fig. 1. Material Characterization; (A) X-ray diffraction of the synthesized magnesium silicate hydrate from hydrothermal method compared to the standard compounds with JCPDS cards of 00-002-1009 and 00-047-1750; (B) FTIR spectrum of synthesized magnesium silicate hydrate; (C) SEM image of the synthesized magnesium silicate; and D) The thickness distribution of the particles of magnesium silicate hydrate

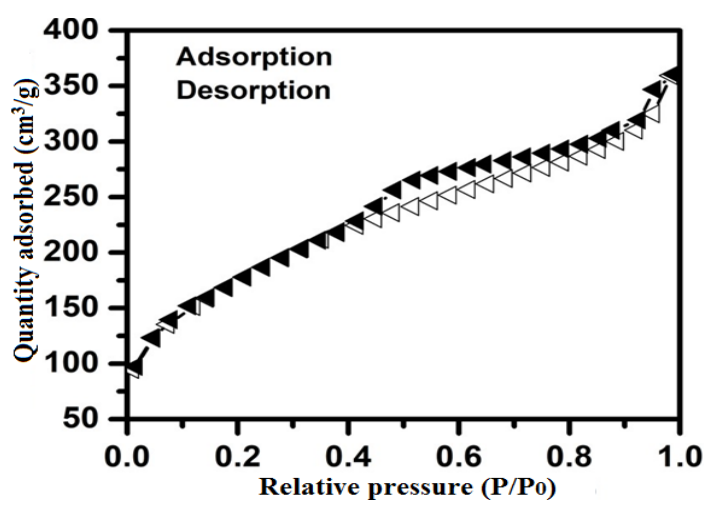

(A)

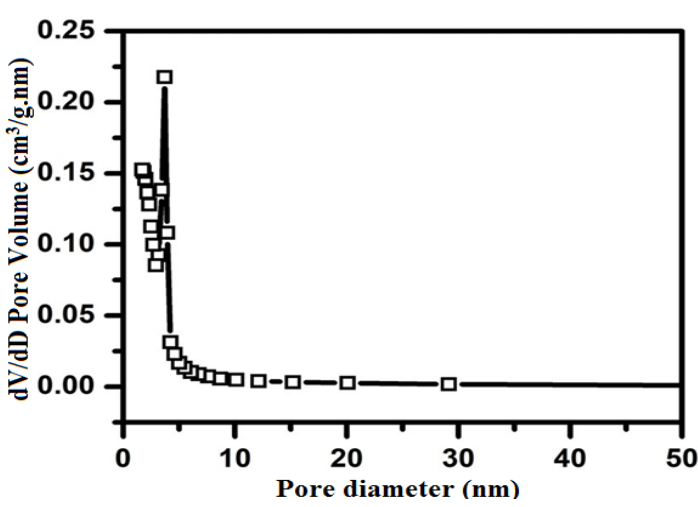

(B)

Fig. 2 (A). Full adsorption and desorption nitrogen isotherms at $77 \mathrm{~K}$ and (B) its corresponding BJH pore size distribution of the prepared magnesium silicate hydrate 


\section{Dye adsorption study}

On the study of dye adsorption capacity and selectivity, the magnesium silicate hydrate was submerged into the aqueous solutions of the dyes, decisively chosen for their structural characteristics, i.e. charges (cationic and anionic dyes), and molecular weights (Fig. 3 A). The adsorption capacity of the synthesized adsorbent, herein magnesium silicate hydrate, for the tested dyes was ranged from lowest to highest as following: MO, RB19, and $M B$. The highest adsorption in the case of MB could be attributed to the compact molecular size of MB $(1.7 \mathrm{~nm} \times 0.76 \mathrm{~nm})^{31}$, making it easier to diffuse into the pores of the magnesium silicate, of which the average pore size is $3.72 \mathrm{~nm}$. Moreover, the other possible factor for excellent adsorption may be originated from the electrostatic attraction between negatively charged surface of the adsorbent and the positive charge on the nitrogen atom within the MB dye. On the contrary, the lower adsorption capacity of other dyes (RB19 and MO (1.2 nm²)) can be explain in part by the electrostatic repulsion between the negative charge on the anionic dyes and the negative charge on the surface of the adsorbent. Also seen from the figure, the adsorption of MB took only $30 \mathrm{~min}$ in order to achieve the saturated adsorption ca. 18.1, while the equilibrated times for the remaining two dyes were longer than 1 hour. Moreover, lower saturated adsorptions were observed for these two dyes.

The $\mathrm{pH}$ of the solution is also an important attribute controlling the adsorption process. The results in (Fig. 3 B) show that the adsorption of MB on magnesium silicate hydrate increases from the value of $6.32 \mathrm{mg} / \mathrm{g}$ to $7.61 \mathrm{mg} / \mathrm{g}$ when reducing the $\mathrm{pH}$ of the solutions from 9 to 5 . The maximum adsorption quantity was found at the $\mathrm{pH}$ of $5(7.61 \mathrm{mg} / \mathrm{g})$ which was in agreement with the previous work reported by Hazzaa, R. and Hussein, M (2014) $)^{33}$. At lower pH, the surface charge may get more positive, according to the dye protonation process by $\mathrm{H}^{+}$ions in the solution. Consequently, this promotes the stronger adsorption of the dye on the negatively-charged surface of the adsorbent than the ones at higher $\mathrm{pH}$. For the effect of the adsorbent dosages on the adsorption rate of $M B$, it was observed that the rate of MB adsorption was less than $15 \mathrm{~min}$ to reach the saturation quantity. As the content of the adsorbents decreased, the rate of equilibrium attainment also decreased
(Fig. $3 \mathrm{C}$ ). This was because of the more available active sites of the adsorbate. All aforementioned arguments reveal that magnesium silicate hydrate is a promising candidate for the selective adsorption of cationic dyes like methylene blue.

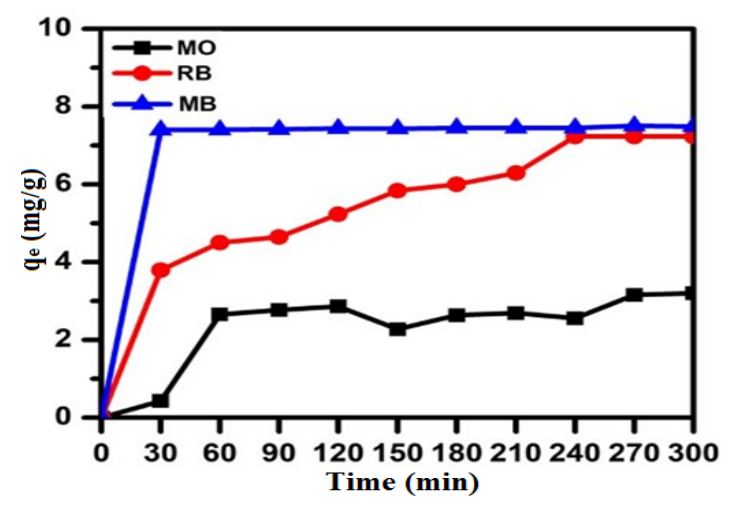

(A)

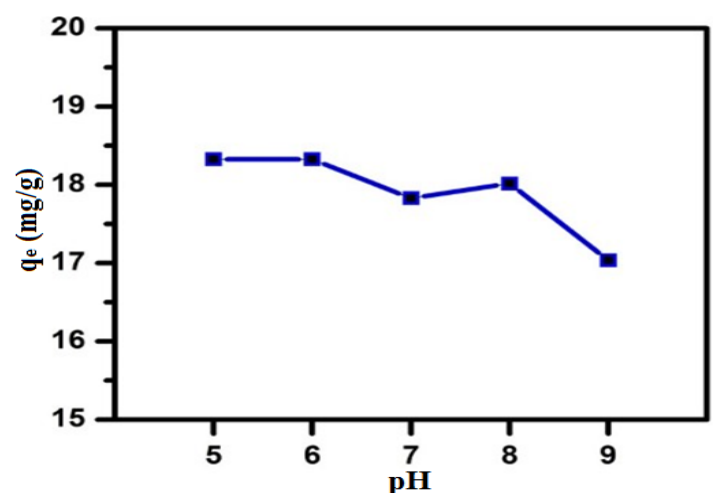

(B)

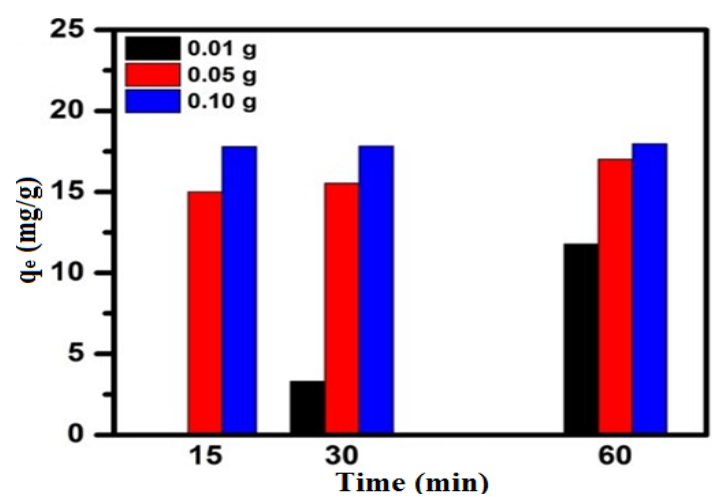

(C)

Fig. 3 (A) Adsorption quantities of different dyes as a function of time; (B) Adsorption quantity of methylene blue as a function of $\mathrm{pH}$ of the dye's solution; (C) Adsorption quantity of methylene blue as a function of adsorbent content. Note that the concentrations of all dyes used in (A) were $50 \mathrm{ppm}$ while the concentration of the MB dye used in (B) and (C) were $100 \mathrm{ppm}$ 


\section{CONCLUSION}

Magnesium silicate hydrate was synthesized by hydrothermal crystallization for using as an adsorbent for commercial organic dyes. The crystalline phase of the prepared adsorbent was identified to be magnesium silicate hydrate by synchrotron-based powder X-ray diffraction (XRD). In addition, characteristic peaks, e.g. $\mathrm{O}-\mathrm{H}$ peaks (stretching and bending) and $\mathrm{Si}-\mathrm{O}-\mathrm{Si}$ vibration observed in the Fourier transform infrared spectroscopy (FTIR) spectrum of the synthesized adsorbent confirmed the result from XRD. The synthesized magnesium silicate was found to have high BET surface area with the value of 634.63 $\mathrm{m}^{2} / \mathrm{g}$ and the average BJH pore size was 3.72 $\mathrm{nm}$. According to nitrogen sorption isotherm, it revealed that there were also mesopores within the synthesized magnesium silicate hydrate which was consequently suitable for dye adsorption. From the dye adsorption study, the synthesized adsorbent showed the strongest capacity to the cationic dye (methylene blue) as a result from the electrostatic attraction between its negatively charged surface and the positively charged dye molecules. Moreover, the adsorption of methylene blue was also reached the equilibrium at the shortest time interval among the other tested dyes. These results showed a possibility for the prepared magnesium silicate hydrate to be used as a selective adsorbent for cationic dyes.

\section{ACKNOWLEDGEMENT}

The authors would like to acknowledge the financial support Kasetsart University Research and Development Institute (KURDI). Appreciation is also expressed to the Department of Materials Engineering, Faculty of Engineering, Kasetsart University. Beamline 1.1W (Multiple X-ray Techniques, MXT) of the Synchrotron Light Research Institute, Nakhon Ratchasima, Thailand, is acknowledged for the XRD beamtime and the facilities during XRD measurements.

\section{Conflict of interest}

There is no conflict of interest to declare.

\section{REFERENCES}

1. Carneiro, P.A.; Nogueira, R.F.P.; Zanoni, M.V.B. Dyes Pigm., 2006, 74(1), 127-132. doi: 10.1016/j.dyepig.2006.01.022.

2. Bafana, A.; Devi, S.S.; Chakrabarti, T. Environ Rev., 2011, 19(1), 350-370. doi:10.1139/a11-018.

3. dos Santos, A.B.; Cervantes, F.J.; van Lier, J. B. Bioresour Technol., 2007, 98(12), 23692385. doi: 10.1016/j.biortech.2006.11.013.

4. Nandhini, N.T.; Rajeshkumar, S.; Mythili, S. Biocatal Agric Biotechnol., 2019, 19, 101138. doi:10.1016/j.bcab.2019.101138.

5. Ogugbue, C.J.; Sawidis, T. Biotechnol Res Int., 2011, 967925. doi:10.4061/2011/967925.

6. Rodríguez Couto, S. Biotechnol Adv. 2009, 27(3), 227-235. doi:10.1016/j.biotechadv. 2008.12.001.

7. Firmino, P.I.M.; da Silva, M.E.R.; Cervantes, F.J.; dos Santos, A. B. Bioresour Technol., 2010, 101(20), 7773-7779. doi:10.1016/j. biortech.2010.05.050.

8. Ma, J.; Wang, R.; Wang, X.; Zhang, H.; Zhu, B.; Lian, L.; Lou, D. J. Environ. Chem. Eng., 2019, 7(3), 103049. doi:10.1016/j. jece.2019.103049.

9. Zhu, C.; Farah, J.; Choël, M.; Gosselin, S.;
Baroudi, M.; Petitprez, D.; Visez, N. Environ Pollut., 2018, 242, 880-886. doi:10.1016/j. envpol.2018.07.025

10. Khumalo, N.P.; Vilakati, G.D.; Mhlanga, S.D.; Kuvarega, A.T.; Mamba, B.B.; Li, J.; Dlamini, D.S. J. Water Process Eng., 2019, 31, 00878. doi:10.1016/j.jwpe.2019.100878.

11. Waghmode, T.R.; Kurade, M.B.; Sapkal, R.T.; Bhosale, C.H.; Jeon, B.-H.; Govindwar, S.P. J. Hazard. Mater., 2019, 115-122. doi:10.1016/j. jhazmat.2019.03.004.

12. Chaari, I.; Fakhfakh, E.; Medhioub, M.; Jamoussi, F. J. Mol. Struct., 2019, 1179, 672677. doi:10.1016/j.molstruc.2018.11.039.

13. Kurtan, U.; Amir, M.;Yildiz, A.; Baykal, A. Appl. Surf. Sci., 2016, 376, 16-25. doi: 10.1016/j. apsusc.2016.02.120

14. Mohebali, S.; Bastani, D.; Shayesteh, H. J. Mol. Struct., 2019, 1176, 181-193. doi: 10.1016/j.molstruc.2018.08.068.

15. Auta, M.; Hameed, B.H. Chem. Eng. J., 2011, 175(1), 233-243. doi: 10.1016/j.cej. 2011.09.100.

16. Tan, I.A.W.; Ahmad, A.L.; Hameed, B.H. J. Hazard. Mater., 2008, 154(1-3), 337-346. doi: 10.1016/j.jhazmat.2007.10.031. 
17. Shamsayei, M.; Yamini, Y.; Asiabi, H. J. Colloid Interface Sci., 2018, 529, 255-264. doi:10.1016/j.jcis.2018.06.022.

18. Ling, F.; Fang, L.; Lu, Y.; Gao, J.;Wu, F.; Zhou, M.; Hu, B. Microporous and Mesoporous Mater., 2016, 234, 230-238. doi:10.1016/j. micromeso.2016.07.015.

19. Ruan, X.; Chen, Y.; Chen, H.; Qian, G.; Frost, R.L. Chem. Eng. J., 2016, 297, 295-303. doi:0.1016/j.cej.2016.01.041.

20. Liu, S.; Li, B.; Qi, P.; Yu, W.; Zhao, J.; Liu, Y. Colloids Interface Sci. Commun., 2019, 28 34-40. doi:10.1016/j.colcom.2018.11.004.

21. Borisover, M.; Davis, J.A. Developments in Clay Science., 2015, 6, 33-70. doi: 10.1016/ B978-0-08-100027-4.00002-4.

22. Xu, R; Mao, J.; Peng, N.; Luo, X.; Chang, C. Carbohydr. Polym., 2018, 188, 143-150. doi:10.1016/j.carbpol.2018.01.073.

23. Bentahar, S.; Dbik, A.; Khomri, M.E.; El Messaoudi, N.; Lacherai, A. Groundwater for Sustainable Development., 2018, 6, 255-262. doi:10.1016/j.gsd.2018.02.002.

24. Zhang, J.; Dang, L.; Zhang, M.; Lu, Q.; Zhao, S. Surf. Interfaces., 2017, 8, 112-118. doi: 10.1016/j.surfin.2017.05.005.

25. Qiu, J.; Feng, Y.; Zhang, X.; Jia, M.; Yao, J. J. Colloid Interface Sci., 2017, 499,151-158.

26. Wattanathana, W.; Veranitisagul, C.; Wanna paiboon, S.; Klysubun, W.; Koonsaeng, N.;
Laobuthee, A. Ceram. Int., 2017, 43(13), 98239830. doi: 10.1016/j.ceramint. 2017. 04. 162.

27. Nantharak, W., Wattanathana, W., Klysubun, W., Rimpongpisarn, T., Veranitisagul, C., Koonsaeng, N., Laobuthee, A. J. Alloys Compd., 2017, 701, 1019-1026. doi:10.1016/j. jallcom.2017.01.090.

28. Veranitisagul, C.;Wattanathana, W.; Nantharak, W.; Jantaratana, P.; Laobuthee, A.; Koonsaeng, N. Mater. Chem. Phys., 2016, 177, 48-55. doi: 10.1016/j.matchemphys.2016.03.038.

29. Wattanathana, W.; Nootsuwan, N.; Veranitisagul, C.; Koonsaeng, N.; Suramitr, S.; Laobuthee, A. J. Mol. Struct., 2016, 1109, 201208. doi: 10.1016/j.molstruc.2015.12.069.

30. Rashid, I.; Daraghmeh, N.H.; Al Omari, M.M.; Chowdhry, B.Z.; Leharne, S.A.; Hodali, H.A.; Badwan, A.A. Profiles Drug Subst Excip Relat Methodol., 2011, 36, 241-285. doi: 10.1016/ B978-0-12-387667-6.00007-5.

31. Li, L.; Liu, X.L.; Gao, M.; Hong, W.; Liu, G.Z.; Fan, L.; Hu, B.; Xia, Q.H.; Liu, L.; Song, G.W.; Xu, Z.S. J. Mater. Chem. A., 2014, 2(6), 17951801. doi: 10.1039/c3ta14225.

32. Wu, Q.-Y.; Liang, H.-Q.; Li, M.; Liu, B.-T.; Xu, Z.-K. Chinese J Polym Sci. (English Edition)., 2016, 34(1), 23-33. doi:10.1007/s10118-016-1723-6.

33. Hazzaa, R.; Hussein, M. Environmental Technology \& Innovation., 2015, 4, 36-51. doi: 10.1016/j.eti.2015.04.002. 